\section{Experimenters Incommunicado}

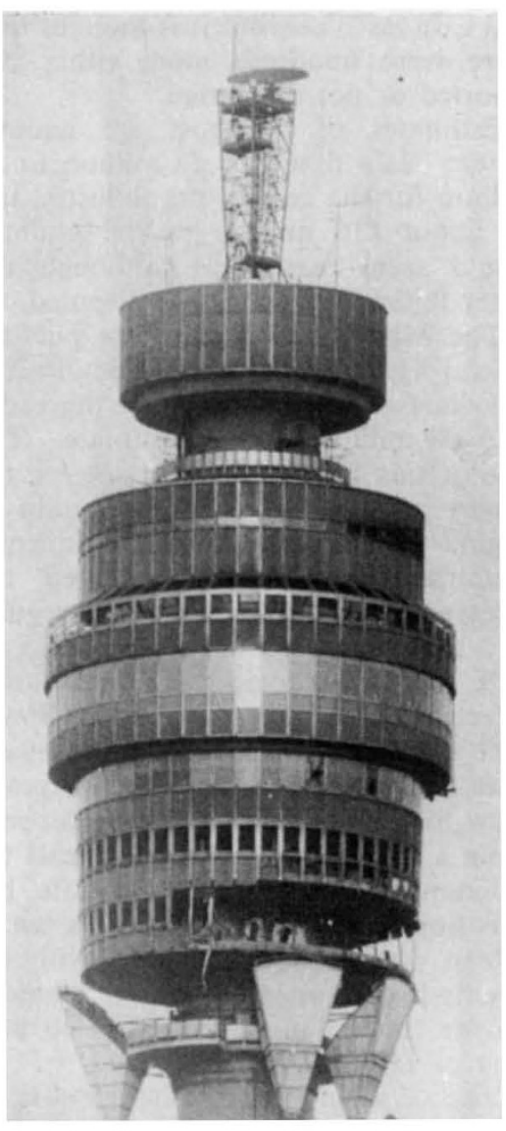

THE characteristics of the Post Office Tower in London under stress have, as is well known, been tested in a recent experiment, the authorship of which is at present unknown even to the London police (see picture). It is less well known that a more carefully controlled study of the building has been carried out by the staff of the Building Research Station and recently published (Strain Measurements at the GPO Tower, London, K. J. Eaton and J. R. Mayne, CP29/71). The lack of communication between the two groups of experimenters will no doubt be regarded as a further sign of interdisciplinary isolation.

\section{STANDARDS}

\section{All Things being Equal}

THE International System of units (SI) was rounded off for the time being by the decisions of the 14th General Conference of Weights and Measures (CGPM) in Paris last month. The conference agreed that the mole should become a base unit of substance within the SI with the pascal and siemens being approved as SI units of pressure and conductance, a pascal being equal to a newton per square metre and a siemens equal to a reciprocal one ohm. The CGPM's forty member states meet at least once every six years to make decisions about units, but its function is really to approve the work of the International Committee on Weights and Measures which meets at least once every two years. Once approved, SI units are published by various bodies throughout the world and by the British Standards Institute (BSI) and HMSO in Britain.

They are also published by the International Organization for Standardization, the international authority on names and symbols for physical quantities and the relation between quantities and units. Seven parts of ISO recommendation $R 31$ have so far been published on quantities and units, with three parts passed for publication and four more in draft.

Before publishing a recommendation, ISO consults national standards organizations and other interested bodies such as the International Union of Pure and Applied Physics, the International Union of Pure and Applied Chemistry and the International Electrotechnology Commission, all of which have their own committees working on standardization of language, symbols and units, and ISO often takes over their agreements. By the time a standard is published it will have been commented on at least two or three times by the interested bodies of the forty or so countries that participate in ISO. As a result, about ten years elapse from the beginnings of agreement on a standard to publication. But the proposed new standards are published and tend to be used before they are officially approved-as has been the case with the SI pascal and siemens.

The future of standards lies simply in efforts to reach greater agreement and in deciding on units and symbols for new fields of science, although, according to Professor McGlashan of the University of Exeter and IUPAC, "more progress has been made in the past twenty years than in the previous ten thousand".

The next meeting of the CGPM in 1975 will celebrate the centenary of the signing of the Metre Convention and it is unlikely that there will be any change made in the base units of SI. The basic work seems over for the moment, but work will no doubt continue in the redefinition of standardsfor example the 10th conference in 1960 redefined the metre as "the length equal to $1,650,763.73$ wavelengths in vacuum of the radiation corresponding to the transition between the levels $2 \mathrm{p}_{10}$ and $5 \mathrm{~d}_{5}$ of the krypton- 86 atom," replacing the definition of 1889 based on the platinum-iridium bar.

\section{WORLD WILDLIFE}

\section{Only Skin-deep}

IN the presence of such personalities as Sir Charles Clore, Lady Gage, Miss Iris Murdoch, the editors of Vogue (both British and American versions), Mrs Rolf Harris and two buyers from Harrods Ltd, Aquascutum, in collaboration with the World Wildlife Fund, revealed its collection of simulated fur fashions earlier this week.

On display, suitably draped around six of the potential Miss Worlds, to the accompaniment of recorded jungle drums and lashings of champagne, were coats made from simulated cheetah, leopard, ocelot and tiger in "styles created especially to celebrate the 10th Anniversary of the World Wildlife Fund". A number of puma and tiger cubs imported for the occasion-presumably to show what the real thing looks like-started off by gambolling around and ended rather frightened at the pressing enthusiasm of their wellwishers.

$\mathrm{Mr}$ Peter Scott, chairman of the British National Appeal, opened the proceedings by saying that he hoped the wearing of real fur will die out as a fashion (cheers), that the Ministry of Defence has agreed not to buy real fur for military drummers to wear (patriotic cheers) and that the sale of the synthetic furs would help conserve those predatory species in danger from man (yet more cheers).

The coats, from man-made fibres cost less than $£ 40$ compared with $£ 1,200$ to $£ 2,000$ for a real ocelot coat. How much do the simulated coats cost to make? Well, Aquascutum for one isn't saying, but judging by the number of women surreptitiously trying them on at the end, they are going to be quite the thing to be seen in. Were they as good as the real thing? Well, no, of course not," said one eager purchaser, slipping out of a (simulated) leopard into a (simulated) cheetah, "but one's friends won't talk to one if you wear real fur ; I mean when there are only 200 left in the world you're not going to be very popular if you appear wearing five of them, are you?"

Meanwhile, back on the dais, Miss World 1969-Miss Eva Reuber-Staierwearing a (simulated) jaguar coat was playing with the young cats to the delight of the adoring multitudes and the frantic photographers--"a little more leg, Miss Ruber-Staier?" Cameras flashed, people cooed, and Peter Scott signed autographs in a corner-simulated fashion furs had definitely arrived.

And if the cats seemed less delighted than the models at the bright lights and brighter people, can you really blame them? 